\title{
Characterising carbon deposited during pyrolysis gasoline hydrogenation: enhanced TPO methodologies
}

\author{
Javed Ali • S. David Jackson
}

Received: 5 February 2014/ Accepted: 17 March 2014/Published online: 5 April 2014

(c) The Author(s) 2014. This article is published with open access at Springerlink.com

\begin{abstract}
In this paper, the use of temperature-programmed oxidation (TPO) is highlighted as a means of interrogating the surface of catalysts. Most studies only concern themselves with the active portion of the catalyst bed; in this study, we examine both the active part and the part that experiences equilibrated gas after reaction. The extent and nature of carbonaceous deposits on both sections of catalyst have been characterised by TPO and reveal that there is significant deposition of low $\mathrm{H}$ :C ratio carbonaceous species on catalyst that has only seen equilibrated reaction gas. This has potential implications for the life of the catalyst bed and the activity and selectivity observed.
\end{abstract}

Keywords PyGas · Hydrogenation - Temperature programmed oxidation · Carbon deposition

\section{Introduction}

Pyrolysis gasoline (PyGas) is a by-product of high temperature naphtha cracking during ethylene and propylene production [1, 2]. It is a mixture of highly unsaturated hydrocarbons ranging from $\mathrm{C}_{5}$ to $\mathrm{C}_{12}$ and contains considerable amounts of aromatics, typically 40-80\% (benzene, toluene and xylene), together with paraffins, olefins and diolefins [3]. Composition of the PyGas produced depends on the feedstock and operating conditions and varies from plant to plant; however, a typical PyGas composition is given in Table 1 [8].

J. Ali · S. D. Jackson ( $\square)$

Department of Chemistry, Centre for Catalysis Research,

WestCHEM, University of Glasgow, G12 8QQ Glasgow,

Scotland, UK

e-mail: david.jackson@glasgow.ac.uk
The main reason for the deactivation of catalysts during PyGas hydrogenation is the deposition of carbonaceous residue (coke) on the surface of the catalyst [10, 11]. The nature of the coke depends on the process conditions and length of reaction with the carbonaceous residues deposited, varying from hydrocarbons and poly-aromatics to graphitic coke. The deposition of coke decreases accessibility for the reactants to the catalyst surface and can block pores. Continued heavy build up of coke in pores may result in fracturing of the support material which can cause plugging of reactor voids [7, 13].

Carbonaceous residue formation is mainly due to the polymerisation of coke precursors present in PyGas such as styrene, di-olefins, mono-olefins, cyclo-olefins and aromatic species [14]. The deposited residue can convert to polyaromatic hydrocarbons, which then further convert to highly condensed polyaromatics and graphitic type coke. This is summarised in Fig. 1 [7, 9].

The nature of the carbonaceous residues also changes with reaction time. The change in the nature of the coke is due to polymerisation, multi-side reactions and loss of hydrogen content. The deposits convert to more condensed and hydrogen deficient coke with the passage of time and then finally form graphitic type coke.

The deposition of coke is highly dependent on the reaction conditions, especially on reaction temperature and hydrogen partial pressure. Increases in the reaction temperature of PyGas hydrogenation not only increase the amount of coke deposition but also result in a more condensed hydrogen deficient coke on the surface. Carbon laydown can be decreased by increasing hydrogen partial pressure [1].

Temperature-programmed oxidation (TPO) is a simple and important technique for the investigation into the quantity and nature of coke deposited [5, 6]. The amount of

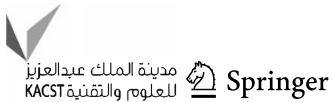


Table 1 Typical composition of PyGas

\begin{tabular}{ll}
\hline PyGas components & Weight percent (wt\%) \\
\hline Benzene, toluene and xylenes & 50 \\
Olefins and dienes & 25 \\
Styrene and other aromatics & 15 \\
Paraffins and naphthenes & 10
\end{tabular}

Coke and gum precursors (styrene, olefins and aromatic)

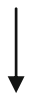

Polymerised hydrocarbons

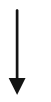

Polyaromatic hydrocarbons

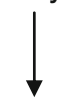

\section{Carbonaceous residues (Coke)}

Fig. 1 Formation of carbonaceous residues (Coke)

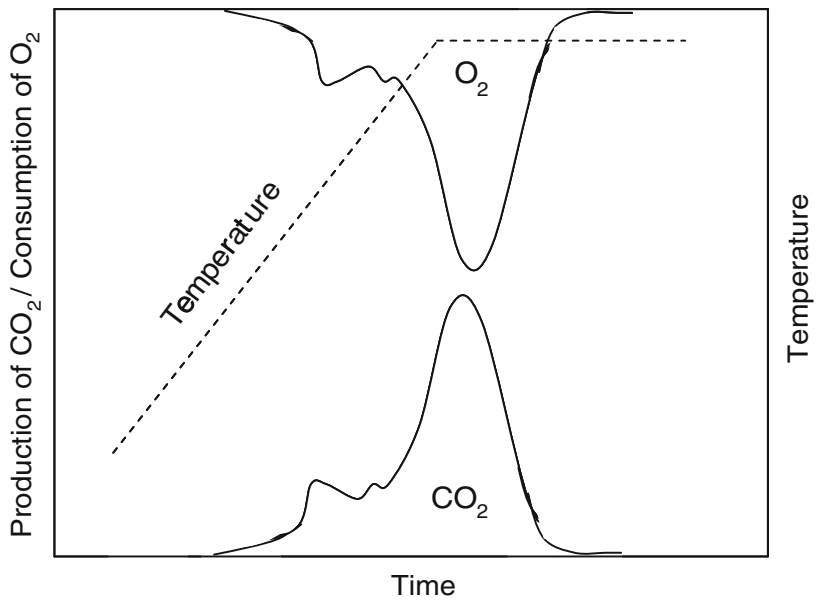

Fig. 2 Typical temperature programme oxidation profile $[5,6]$

oxygen consumed and the amount of $\mathrm{CO}_{2} / \mathrm{CO}$ produced indicate the amount of coke deposited on the surface of the catalyst. The oxygen consumption is commonly mirrored by the production of $\mathrm{CO}_{2}$, as shown in Fig. 2 .

The combustion of hydrogen rich coke, which is mostly present on the catalytic metal, occurs first. This is followed by the combustion of the hydrogen deficient coke present on the surface of the catalyst $[4,12]$. The ratio of $\mathrm{CO}_{2} / \mathrm{H}_{2} \mathrm{O}$ and/or $\mathrm{CO} / \mathrm{H}_{2} \mathrm{O}$ can give insight into the carbon to hydrogen ratio present in the coke. A decrease in hydrogen
Table 2 Catalyst specifications

\begin{tabular}{lllll}
\hline Catalyst & $\begin{array}{l}\text { Metal } \\
\text { loading } \\
(\% \mathrm{wt})\end{array}$ & $\begin{array}{l}\text { Metal } \\
\text { dispersion } \\
(\%)\end{array}$ & $\begin{array}{l}\text { Surface area } \\
\left(\mathrm{m}^{2} \mathrm{~g}^{-1}\right)\end{array}$ & $\begin{array}{l}\text { Pore volume } \\
\left(\mathrm{cm}^{3} \mathrm{~g}^{-1}\right)\end{array}$ \\
\hline $\mathrm{Ni} / \mathrm{Al}_{2} \mathrm{O}_{3}$ & 16.0 & 18.0 & 106 & 0.39 \\
\hline
\end{tabular}

to carbon ratio represents more condensed polyaromatic type of coke [6].

In this paper, we use TPO to probe the carbon deposit in both the reaction zone and the rest of the catalyst bed that is subjected to equilibrated gas in the typical fixed bed configuration found in the most chemical plants.

\section{Experimental}

The $\mathrm{Ni} / \mathrm{Al}_{2} \mathrm{O}_{3}$ (HTC 400) catalyst used in this project was provided by Johnson Matthey. The characterisation data of catalyst provided by catalyst manufacturer are shown in Table 2.

Hydrogenation of the synthetic pyrolysis gasoline (PyGas) was investigated over the $\mathrm{Ni} / \mathrm{Al}_{2} \mathrm{O}_{3}$ catalyst in a fixedbed, high-pressure, continuous flow reactor. The catalyst (particle size between 250 and 425 microns) was added to the reactor tube and positioned in the middle of reactor tube. The catalyst was reduced in situ with a flow of hydrogen gas. The $\mathrm{Ni} / \mathrm{Al}_{2} \mathrm{O}_{3}$ catalyst was reduced for $16 \mathrm{~h}$ at a temperature of $723 \mathrm{~K}$. Following this, the reactor temperature was decreased to the required reaction temperature $(413 \mathrm{~K})$. The reactor was then pressurised to the desired pressure (20 barg). Once the reactor had obtained the desired conditions, the reaction was started with a particular flow of PyGas feed of $0.042 \mathrm{ml} \mathrm{min}^{-1}$ $\left(\right.$ WHSV $_{\text {PyGas }} 8 \mathrm{~h}^{-1}$ ) and a flow of $\mathrm{H}_{2} / \mathrm{N}_{2}$ gas $\left(10 \mathrm{ml} \mathrm{min}^{-1}\right)$. The PyGas was vaporised and mixed with hydrogen and then passed through the catalyst bed. The hydrogenated PyGas was condensed in a knockout pot, which was chilled to $273 \mathrm{~K}$. Liquid samples were collected every $2 \mathrm{~h}$ during daytime and analysed using a Thermo Finnigan Focus G.C. The hydrogenated PyGas mainly condensed in the knockout pot; however, very small amounts of the reaction products remained in the gaseous phase and, therefore, the effluent gas was also analysed at regular intervals by online Agilent G.C. All reactions were run for $76 \mathrm{~h}$. After finishing each reaction, nitrogen gas was passed through the catalyst over night so as to remove any species present in the reactor. The reactor was then cooled to room temperature in the flow of nitrogen gas and then an in situ TPO was performed on the post reaction catalyst. The gas was switched to a flow of $2 \% \quad \mathrm{O}_{2} / \mathrm{Ar}$ $\left(40 \mathrm{ml} \mathrm{min}{ }^{-1}\right)$ and the temperature increased to $723 \mathrm{~K}$ at a ramp of $5 \mathrm{~K} \mathrm{~min}^{-1}$ and then the reactor temperature was held constant at $723 \mathrm{~K}$ until all evolution of gases other 
Table 3 Weight percent (\%) composition of PyGas

\begin{tabular}{llllllll}
\hline Components & 1-pentene & Cyclopentene & 1-octene & Toluene & Styrene & Heptane & Decane \\
\hline PyGas wt $\%$ & 10.0 & 10.0 & 10.0 & 55.0 & 10.0 & 2.5 & 2.5 \\
\hline
\end{tabular}

than $\mathrm{O}_{2}$ and Ar ceased. The TPO process was monitored by an online mass spectrometer (QMS) in which the ion current of main species of mass fragments with $\mathrm{m} / \mathrm{z} 28$ (CO), $44\left(\mathrm{CO}_{2}\right), 32\left(\mathrm{O}_{2}\right), 18\left(\mathrm{H}_{2} \mathrm{O}\right)$ was monitored. Other species with $\mathrm{m} / \mathrm{z} 68$ (cyclopentene), 70 (1-pentene), 72 (pentane), 78 (benzene), 92 (toluene), 98 (methylcyclohexane), 104 (styrene), 106 (ethylcyclo-hexane), 112 (1-octene), 114 (octane), $15\left(\mathrm{CH}_{3}\right), 29\left(\mathrm{C}_{2} \mathrm{H}_{5}\right)$ and $2\left(\mathrm{H}_{2}\right)$ were also followed for detailed investigation of deposited coke.

A synthetic PyGas was used in this study and the composition is shown in Table 3. No benzene was used in this mix due to health and safety concerns: toluene was

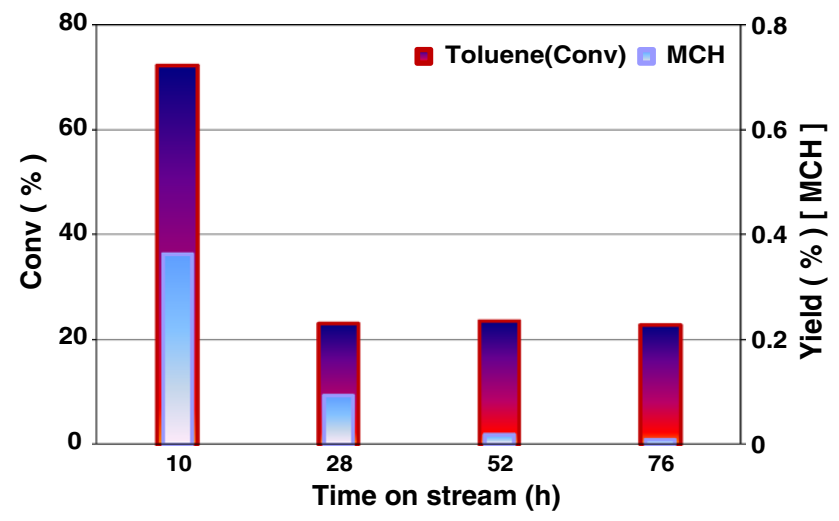

Fig. 3 Deactivation profile for toluene hydrogenation (component part of PyGas). Conditions: $413 \mathrm{~K}$, WHSV $8 \mathrm{~h}^{-1}, \mathrm{H}_{2}$ pressure 5 barg, $\mathrm{H}_{2}$ :PyGas molar ratio $=5$, overall pressure 20 barg used as a replacement. Heptane and decane were used as internal standards for GC analysis.

\section{Results and discussion}

During the course of the time on stream (TOS), the catalyst deactivated. A typical deactivation profile is shown in Fig. 3 with the hydrogenation of toluene to methylcyclohexane. There is a rapid deactivation over the first $24 \mathrm{~h}$ followed by a period of much slower deactivation. This behaviour was observed with all reactants. At the end of the 76-h TOS, the catalyst was subjected to an in situ TPO. The evolution of carbon dioxide and water is shown in Fig. 4, while the evolution of more complex species is shown in Fig. 5. In general, aliphatic species were not observed.

These graphs show that there has been considerable carbon deposition and that species such as benzene, which was not present in the feed, can be formed on the surface of the catalyst. As expected, the main species detected are aromatics, and very little of the fully hydrogenated species such as methylcyclohexane are seen.

In a typical fixed bed reactor on a chemical plant, the product flow will pass over a significant amount of catalyst that has been added to the reactor but only comes into action as the front end of the bed is deactivated. It is generally assumed that this part of the bed is unaffected by the product gases and is in a similar
Fig. 4 Evolution of water and carbon dioxide as a function of temperature during TPO

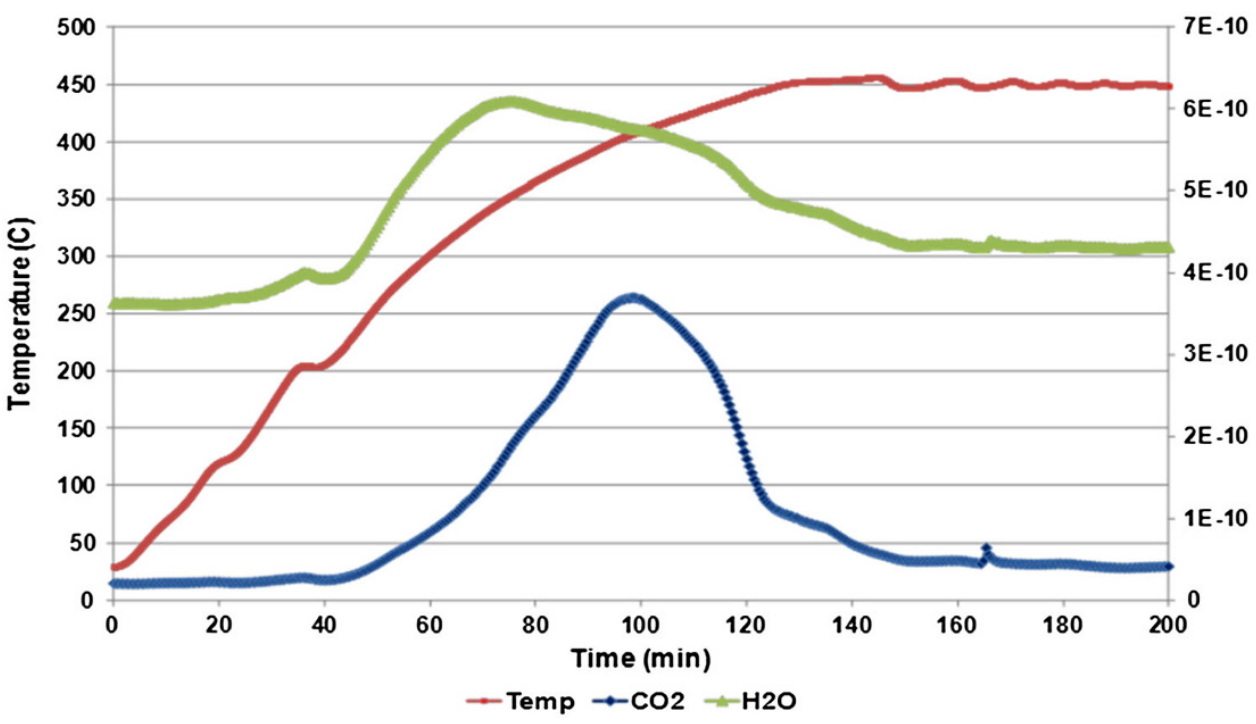


Fig. 5 Evolution of complex species during TPO

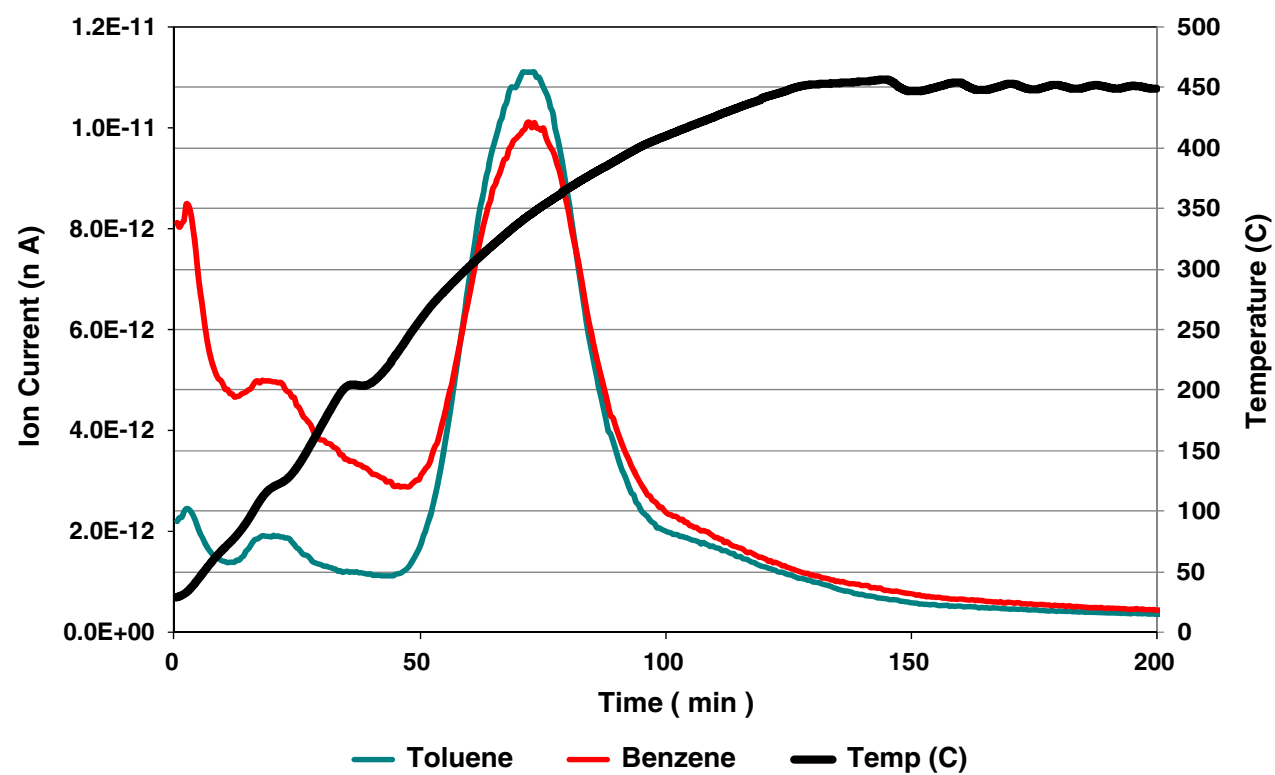

Table 4 Conversion of PyGas components at normal-bed and extended-bed positions

\begin{tabular}{lll}
\hline Conversion $(\%)$ & Extended bed & Normal bed \\
\hline 1-pentene & 90.6 & 87.3 \\
1-octene & 98.3 & 99.3 \\
Cyclopentene & 93.8 & 93.1 \\
Toluene & 24.1 & 23.1 \\
Styrene & 99.9 & 99.9
\end{tabular}

Conditions: $413 \mathrm{~K}, 20$ barg pressure, 5 barg hydrogen, $\mathrm{H}_{2}:$ PyGas molar ratio $=5$

normal-bed profiles are shown in Figs. 4 and 5. The extended-bed profiles are shown in Figs. 7 and 8. It is immediately clear that the profiles for the carbon dioxide and water have significantly altered. In Fig. 9, both the carbon dioxide evolution profiles for the normal and extended bed are compared. The carbon dioxide profile for the extended bed reveals that there has been considerable carbon deposition on the "unreactive" part of the bed and this is especially noticeable at the higher temperatures. By $450{ }^{\circ} \mathrm{C}$, carbon dioxide evolution has almost ceased with the normal bed, whereas there is still significant amount of carbon combusting with the extended bed. The water profile is also different. The water evolution from the normal bed covers the same temperature range as the carbon dioxide, although the specific shape is different indicating a variety of carbonaceous species on the surface with different $\mathrm{H}: \mathrm{C}$ ratios. However, the water profile from the extended bed does not mirror the temperature range of the carbon dioxide. In this case, the water evolution peaks at $350{ }^{\circ} \mathrm{C}$ and is almost back to 
Fig. 7 Evolution of water and carbon dioxide as a function of temperature during TPO with an extended bed

Fig. 8 Evolution of complex species during TPO with an extended bed
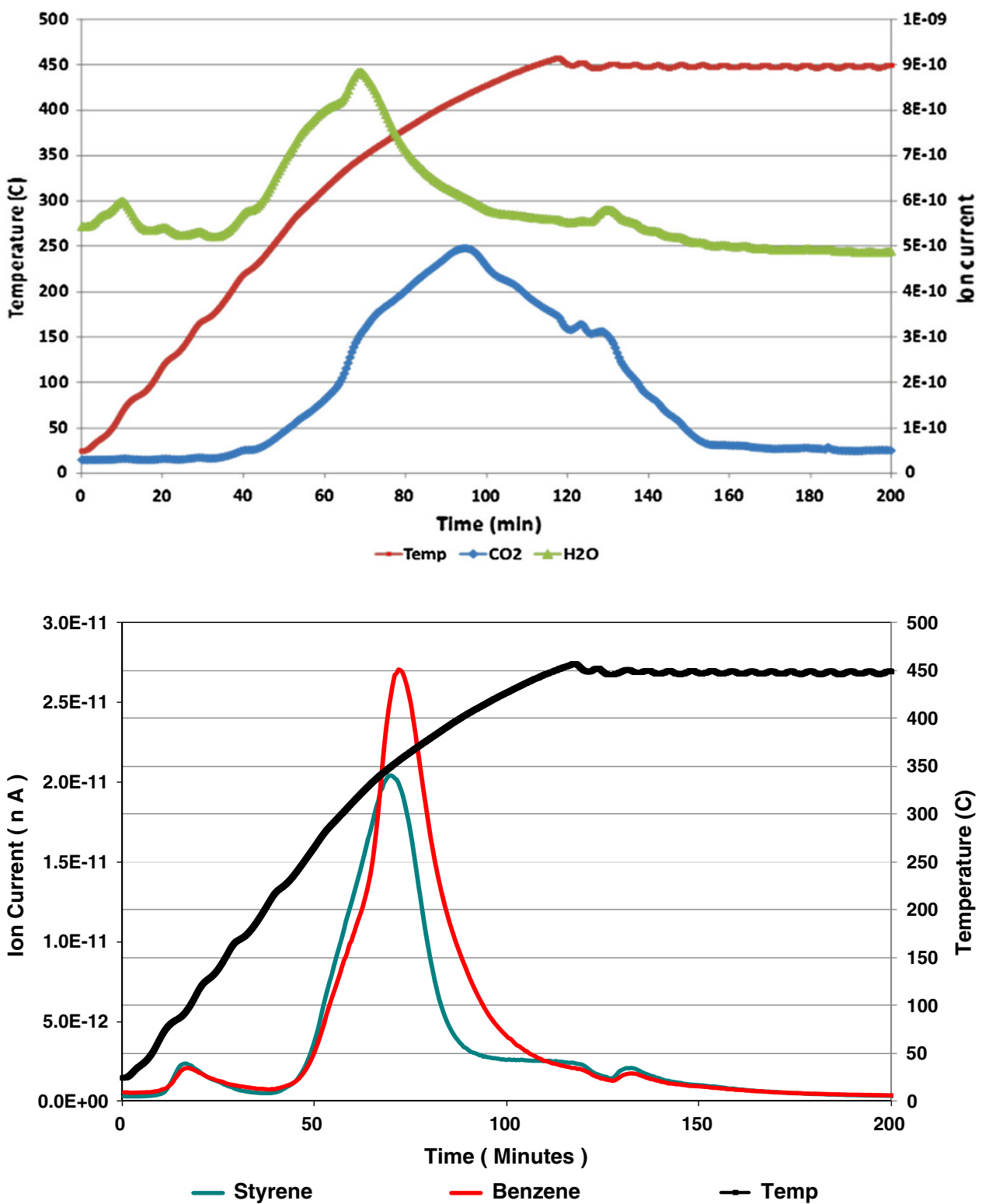

baseline by $450{ }^{\circ} \mathrm{C}$. This change can give information related to the $\mathrm{C}: \mathrm{H}$ ratio of the carbonaceous deposit. The carbonaceous deposit that is combusted at $450{ }^{\circ} \mathrm{C}$ on the extended bed produces carbon dioxide but very little water indicating that the deposit has a low $\mathrm{H}: \mathrm{C}$ ratio, $<1$ suggesting the formation of polyaromatic or graphitic-like species. Note that this material is deposited in an atmosphere that has much less free hydrogen than that at the start of the bed. Even though much of the organic feed is now saturated, the lower gas phase hydrogen concentration does appear to affect the $\mathrm{H}: \mathrm{C}$ ratio in a negative way. From the comparison of the water and carbon dioxide profiles, it is clear that on the normal bed the carbonaceous deposit has a much higher $\mathrm{H}: \mathrm{C}$ ratio over the full profile and hence is easier to combust at lower temperatures.
In Fig. 10, the profiles obtained from benzene and toluene are compared and it can be seen that the extended bed has significantly more aromatic species than the normal bed but there is no evidence for desorption at higher temperatures.

\section{Conclusions}

Therefore using this enhanced TPO methodology, we have been able to show that in a standard fixed bed reactor, passing reaction equilibrated gas over fresh catalyst does not necessarily inhibit carbonaceous deposition and that the species deposited may be more deleterious to the catalyst activity than that deposited under reaction chemistry. This has potential implications for catalyst life in the plant and 
Fig. 9 Comparison of carbon dioxide and water evolution from the normal (NB) and extended (EB) beds

Fig. 10 Comparison of benzene and toluene evolution from the normal (NB) and extended (EB) beds
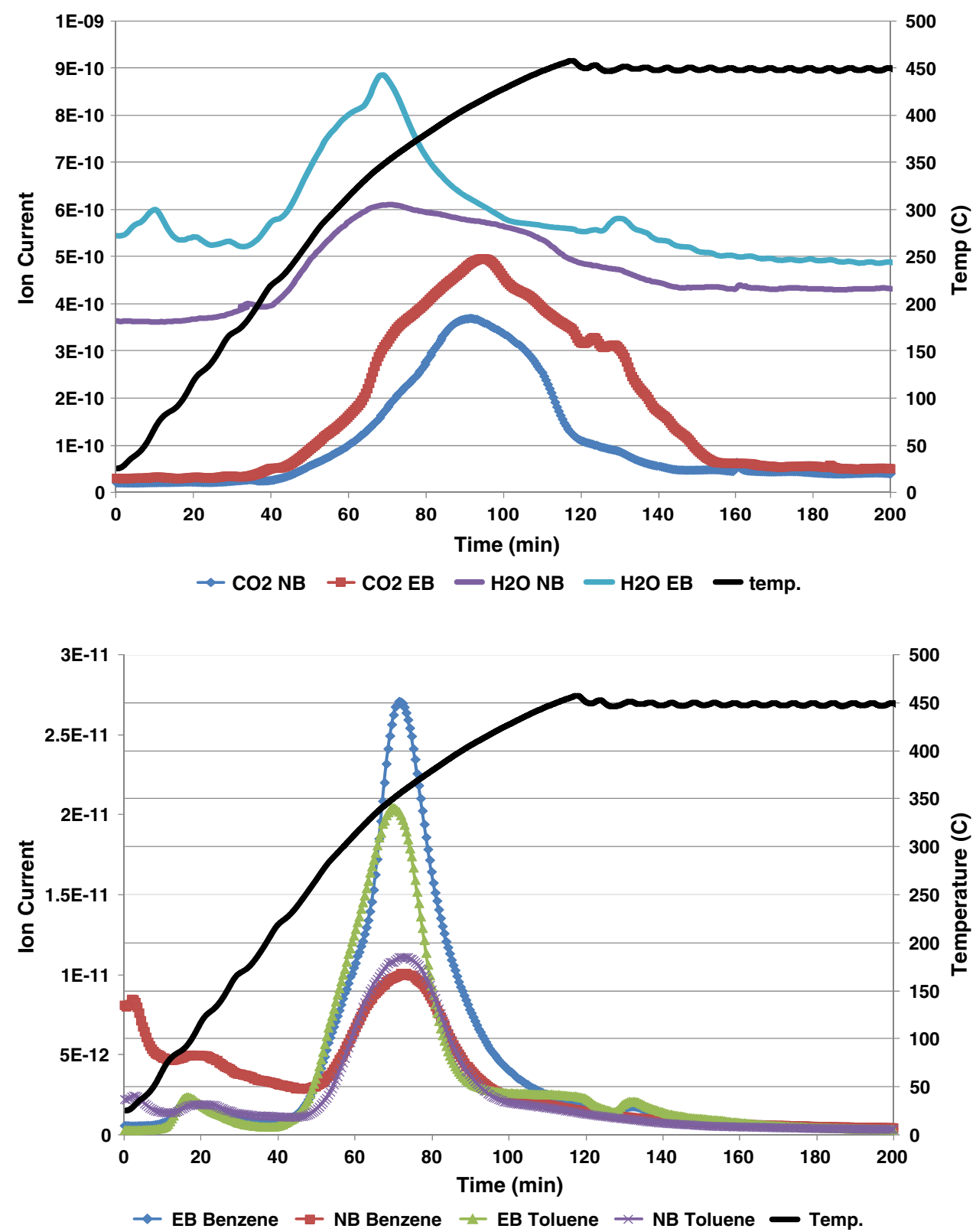

on the expected activity and selectivity. Using these techniques, a better understanding of the catalyst operating in the plant can be obtained.

Open Access This article is distributed under the terms of the Creative Commons Attribution License which permits any use, distribution, and reproduction in any medium, provided the original author(s) and the source are credited.

\section{References}

1. Cheng YM, Chang JR, Wu JC (1986) Appl Catal 24:273-285

2. Reddy KM, Pokhriyal SK, Ratnasamy P, Sivasanker S (1992) Appl Catal A 83:1-13
3. (1979) US Patent 4150061, Process for converting pyrolysis gasoline to benzene and ethylbenzene-lean xylenes; assigned to Standard Oil Company (Indiana)

4. Anderson JA, Garcia MF (2005) Supported metals in catalysis. Imperial College Press, London

5. Barbier J (1986) Appl Catal 23:225-243

6. Barbier J, Churin E, Parera JM, Riviere J (1985) React Kinet Catal Lett 29:323-330

7. Bartholomew CH (2001) Appl Catal A 212:17-60

8. de Medeiros JL, Araujao OQF, Gaspar AB, Silva MAP, Britto JM (2007) Braz J Chem Eng 24:119-133

9. Hagen J (2006) Industrial catalysis: a practical approach, 2nd edn. Wiley-VCH, Mannheim

10. Le Page JF, Cosyns J, Courty EFP, Marcilly C, Martino JMG, Montarnal R, Sugier A, Landeghem HV (1987) Applied heterogeneous catalysis: design, manufacture, use of solid catalyst. Technip, Paris 
11. Lloyd L (2008) Handbook of industrial catalysts. Springer, London

12. Porta F, Rossi M (2003) J Mol Catal A Chem 204-205:553-559

13. Richardson JT (1989) Principles of catalyst development. Plenum Press, New York
14. Weitkamp J, Raichle A, Traa Y (2001) Appl Catal A 222:277-297 